\title{
Human desmoid fibroblasts: matrix metalloproteinases, their inhibitors and modulation by Toremifene
}

\author{
Chiara Balducci ${ }^{1}$, Cinzia Lilli ${ }^{1}$, Giordano Stabellini ${ }^{2}$, Lorella Marinucci ${ }^{1}$, \\ Giammario Giustozzi ${ }^{3}$, Alessio Becchetti ${ }^{3}$, Lucio Cagini ${ }^{3}$ and Paola Locci*1
}

\author{
Address: ${ }^{1}$ Department of Experimental Medicine and Biochemical Science, University of Perugia, Perugia, Italy, ${ }^{2}$ Department of Human Anatomy, \\ University of Milan, Milan, Italy and ${ }^{3}$ Department of Surgery, University of Perugia, Perugia, Italy \\ Email: Chiara Balducci - chiara.balducci@tiscali.it; Cinzia Lilli - ististem@unipg.it; Giordano Stabellini - stg@unife.it; \\ Lorella Marinucci - ististem@unipg.it; Giammario Giustozzi - ggiustoz@yahoo.it; Alessio Becchetti - ististem@unipg.it; \\ Lucio Cagini - giammgiu@tin.it; Paola Locci* - locci@unipg.it \\ * Corresponding author
}

Published: 0I March 2005

BMC Cancer 2005, 5:22 doi:10.1/86//47|-2407-5-22
Received: 13 January 2004

Accepted: 0I March 2005

This article is available from: http://www.biomedcentral.com/I47I-2407/5/22

(c) 2005 Balducci et al; licensee BioMed Central Ltd.

This is an Open Access article distributed under the terms of the Creative Commons Attribution License (http://creativecommons.org/licenses/by/2.0), which permits unrestricted use, distribution, and reproduction in any medium, provided the original work is properly cited.

\begin{abstract}
Background: Desmoid tumour is a benign, non metastasising neoplasm characterised by an elevated deposition of organic macromolecules in the extracellular matrix (ECM). The matrix metalloproteinases (MMPs) are a family of zinc-dependent proteinases involved in the degradation of ECM macromolecules. The MMPs and their natural inhibitors (TIMPs) have been implicated in tumour growth, invasion and metastasis. In this study we provide evidence that the in vitro cultured cell line from desmoid tumour accumulates more collagen fibres in the ECM than healthy fibroblasts.
\end{abstract}

Methods: We investigated collagen accumulation by ${ }^{3} \mathrm{H}$-thymidine incorporation, MMP expression by substrate gel zymography and TIMP expression by Western blot analysis.

Results: Desmoid fibroblasts showed a reduction in MMP activity and an increase of type I and III collagen and TIMPs compared to normal fibroblasts.

Conclusion: The increase in collagen in desmoid fibroblasts was due to inhibited collagen degradation (reduction of MMP activity) rather than to increased collagen synthesis. Adding toremifene, an anti-estrogen triphenylethylene derivate, to desmoid fibroblasts reduced collagen accumulation by decreasing mRNA expression and increasing collagen degradation.

\section{Background}

Desmoid tumours, which are frequently observed in Gardner's syndrome, are rare, slow-growing, histologically benign tumours caused by autosomal dominant gene mutation $[1,2]$. They are, however, locally aggressive, compress surrounding structures and show frequent recurrences after surgical removal. Desmoid cells are characterized by abundant deposition of organic macromole- cules in the extracellular matrix (ECM), by enhanced transforming growth factor $\beta_{1}$ (TGF $\left.\beta_{1}\right)$ gene expression and increased protein secretion [3]. Cell proliferation, angiogenesis and the accumulation of ECM macromolecules are all facilitated by tumour cell production of TGF $\beta_{1}$ [3-6]. All components of ECM are degraded by matrix metalloproteinases (MMPs), a family of zincdependent neutral endopeptidases [7]. Two types of 
MMPs are required for dissolution of interstitial collagen: collagenases and gelatinases [8]. Collagenase-1 (MMP-1), collagenase-2 (MMP-8) and collagenase-3 (MMP-13) are the principal secreted neutral proteinases that initiate degradation of native fibrillar collagens of type I, II, III and V. They all cleave fibrillar collagens at a specific site, resulting in the generation of $\mathrm{N}$-terminal $3 / 4$ and C-terminal $1 / 4$ fragments, which are further degraded by gelatinases $[7,9,10]$. Gelatinase-A (MMP-2) is expressed by several types of cells, especially fibroblasts, whereas gelatinase-B (MMP-9) is restricted to epithelial cells. MMP-2 and MMP-9 are thought to play major roles in the final degradation of fibrillar collagens after first cleavage by collagenases and denaturation [11]. MMP-2 also cleaves native type I collagen to N-terminal 3/4 and C-terminal 1/4 fragments which are identical to those generated by collagenases [12]. Several different tissue inhibitors of matrix metalloproteinases (TIMPs; TIMP-1 to TIMP-4) have been identified as the major natural inhibitors of MMPs [13]. TIMP-1 and TIMP-2 inhibit the activity of most MMPs [11]. Expression of TIMP-1 is up-regulated at the transcription level by various growth factors such as TGF $\beta_{1}$, whereas TIMP-2 is largely expressed constitutively by cultured cells [14]. Our previous studies showed desmoid fibroblasts enhanced deposition of organic macromolecules in the ECM and TGF $\beta_{1}$ secretion [3]. Even if desmoid cells do not have estrogen receptors [3], adding toremifene, an antiestrogenic triphenylethylene derivate, decreased TGF $\beta_{1}$ production and ECM macromolecule accumulation through a mechanism of action that still remains unclear $[3,6,15,16]$. The present study investigates the rule of MMPs and TIMPs in the desmoid tumour and describes, for the first time, the effects of toremifene on MMPs and TIMPs. The results provided evidence that toremifene reduced ECM accumulation by decreasing collagen synthesis and increasing collagen degradation.

\section{Methods}

\section{Antiestrogen}

Toremifene

(4-chloro-1,2-diphenyl-1- $\{4-[2-(\mathrm{N}, \mathrm{N}-$ dimethylamino) ethoxy] phenyl $\}$-1-butene) citrate was purchased from Farmos (Farmos Group Ltd, Finland).

\section{Cell cultures}

Fibroblast cell lines were obtained from patients with Gardner's syndrome and were provided by NIGMS (Camden, N.J.). The GMO 6965 cell line was obtained from phenotypically healthy fibroblasts, and the GMO 6888 cell line was obtained from desmoid fibroblasts. All cell lines were cultured in Eagle's minimal essential medium (MEM) (Sigma, St. Louis, MO) supplemented with 20\% fetal bovine serum (FBS) (GIBCO-Invitrogen, Basel, Switzerland), 2\% non-essential amino acids (GIBCO), $2 \mathrm{mM}$ L-glutamine, $100 \mathrm{U} / \mathrm{ml}$ penicillin and $100 \mathrm{U} / \mathrm{ml}$ streptomycin in a humidified $5 \% \mathrm{CO}_{2}$ atmosphere at $37^{\circ} \mathrm{C}$. Con- fluent cultures were obtained after $48 \mathrm{~h}$ of in vitro maintenance. The cells were cultured for $12 \mathrm{~h}$ in MEM. The medium was then discarded to avoid serum factor contamination. Toremifene was dissolved in ethanol and all the cultures were maintained in MEM containing ethanol or MEM containing toremifne in ethanol and treated as described below.

\section{Cell viability}

Normal (control) and desmoid fibroblasts were cultured for $24 \mathrm{~h}$ in MEM and ethanol or MEM containing $1 \mu \mathrm{M}$ toremifene in ethanol (final concentration $0.1 \% \mathrm{v} / \mathrm{v}$ ). Then $50 \mu$ l of sterile $0.4 \%$ trypan blue solution (final concentration $0.05 \%$ ) was added to each culture well; cultures were incubated at $37^{\circ} \mathrm{C}$ for $15 \mathrm{~min}$. Viable cells (trypan blue negative) and dead cells (trypan blue positive) were counted by a Burker chamber.

\section{Collagen synthesis}

Confluent cultures of normal (GMO 6965) and desmoid fibroblasts (GMO 6888) were cultured for 3, 24 and $48 \mathrm{~h}$ in MEM without serum supplemented L-ascorbic acid (50 $\mu \mathrm{g} / \mathrm{ml}), \quad \beta$-aminopropionitrile fumarate $(50 \mu \mathrm{g} / \mathrm{ml}), 8$ $\mu \mathrm{Ci} / \mathrm{ml}$ of ${ }^{3} \mathrm{H}$-proline (specific activity $35 \mathrm{Ci} / \mathrm{mmole}$, Amersham, Freiburg, Germany) in the presence or absence of $1 \mu \mathrm{M}$ toremifene. In a second set of experiments desmoid fibroblasts were cultured in MEM supplemented with L-ascorbic acid $(50 \mu \mathrm{g} / \mathrm{ml}), \quad \beta$ aminopropionitrile fumarate $(50 \mu \mathrm{g} / \mathrm{ml})$ for $48 \mathrm{~h}$ with or without toremifene. ${ }^{3} \mathrm{H}$-proline was added for $48 \mathrm{~h}$, for the last 24 and for the last $3 \mathrm{~h}$. At the end of the labelling period collagen was extracted using the method of Webster and Harvey [17]. Samples were digested with pepsin $(1 \mathrm{mg} / \mathrm{ml})$ in mild agitation overnight at $4^{\circ} \mathrm{C}$. Collagen was precipitated and redissolved in $500 \mu \mathrm{l}$ cold acetic acid $0.5 \mathrm{M}$. Total radioactivity was counted in a liquid scintillation counter and expressed as cpm/ $\mathrm{\mu g}$ protein.

\section{Northern blot analysis of procollagen $\alpha_{I}(I)$}

Total RNA was isolated from confluent cultures of normal and desmoid fibroblasts maintained for $48 \mathrm{~h}$ in MEM alone or supplemented with $1 \mu \mathrm{M}$ toremifene using the method of Chomczynski and Sacchi [18]. For Northern blot analysis equal amounts of total RNA (20 $\mu \mathrm{g})$ were electrophoresed on $1 \%$ agarose gel containing $0,66 \mathrm{M}$ formaldehyde and transferred on to nylon filters (Hybond $\mathrm{N}$, Amersham). Before blotting, the gel was rinsed in water for $15 \mathrm{~min}$ at room temperature and then in 20X SSC ( $1 \mathrm{X}$ $\mathrm{SSC}$ is $0.15 \mathrm{M}$ sodium chloride, $0.015 \mathrm{M}$ sodium citrate, $\mathrm{pH} 7$ ) for $10 \mathrm{~min}$. Blots were pre-hybridised in $20 \mathrm{ml}$ of a cocktail containing $1 \mathrm{mM}$ EDTA pH 8, $0.25 \mathrm{M} \mathrm{Na}_{2} \mathrm{HPO}_{4}$ $\mathrm{pH} 7.2$ and $7 \%$ sodium dodecyl sulfate (SDS) for $4 \mathrm{~h}$ at $65^{\circ} \mathrm{C}$. Probes were labelled with $[\alpha-32 \mathrm{P}] \mathrm{dCTP}(3000 \mathrm{Ci} /$ $\mathrm{mM}$ ) by random priming (Amersham RPN 1601). Hybridisation was performed at $65^{\circ} \mathrm{C}$ overnight using 
$10^{6} \mathrm{cpm} / \mathrm{ml}$ probe in the same buffer used for pre-hybridisation. After hybridisation, the nylon membrane was washed twice in $1 \mathrm{mM}$ EDTA pH $8,20 \mathrm{mM} \mathrm{Na}_{2} \mathrm{HPO}_{4} \mathrm{pH}$ 7.2 and $5 \%$ SDS at $65^{\circ} \mathrm{C} \mathrm{(5} \mathrm{min} \mathrm{each)} \mathrm{and} \mathrm{then} \mathrm{washed}$ twice with $1 \mathrm{mM}$ EDTA pH 8, $20 \mathrm{mM} \mathrm{Na}_{2} \mathrm{HPO}_{4} \mathrm{pH} 7.2$ and $1 \%$ SDS at $65^{\circ} \mathrm{C}(5 \mathrm{~min}$ each). The filters were stripped and re-hybridised with a GAPDH probe to assess blot loading. For autoradiography the membranes were exposed to Kodak X-Omat film (Rochester, NY) at $-80^{\circ} \mathrm{C}$ for 1 day. Autoradiographies were analysed by computerised scanning densitometry. Results are expressed as the ratio of procollagen $\alpha 1$ (I)/control GAPDH densitometry signals.

\section{cDNA probes}

A 670 bp Eco RI-Hind III cDNA fragment from human pro-collagen $\alpha 1$ (I) and a $1.3 \mathrm{~kb}$ PstI cDNA fragment from rat glyceraldehyde-3-phosphate dehydrogenase were used as probes in hybridisation [18].

\section{Collagenase activity}

Collagenase activity was determined using the method of Khorramizadeh et al., [19]. Confluent normal and desmoid fibroblasts were washed with MEM and cultured for $48 \mathrm{~h}$ in MEM or in MEM containing $1 \mu \mathrm{M}$ toremifene. Proteins in the medium were precipitated by ammonium sulphate $65 \% \mathrm{w} / \mathrm{v}$; precipitates were collected by centrifugation, dissolved in assay buffer $(0.05 \mathrm{M}$ Tris- $\mathrm{HCl}, 0.2 \mathrm{M}$ $\mathrm{NaCl}, 5 \mathrm{mM} \mathrm{CaCl}_{2}, 0.02 \%$ sodium azide, $\mathrm{pH} 7.4$ ) and then dialysed overnight against the same buffer. The latent procollagenase was activated with trypsin $(10 \mu \mathrm{g} /$ $\mathrm{ml}$ ) and then the trypsin was inactivated with soybean trypsin inhibitor $(100 \mu \mathrm{g} / \mathrm{ml})$. Acetic acid soluble type I collagen $(25 \mu \mathrm{l}$ of a solution $2 \mathrm{mg} / \mathrm{ml})$ from bovine skin was incubated with the activated collagenase solution for $24 \mathrm{~h}$. The products of the collagen digestion were separated by electrophoresis using $6 \%$ acrylamide gel containing SDS. The gels were stained with $0.25 \%$ Coomassie brilliant blue G-250 (50\% methanol, 10\% acetic acid), destained appropriately (40\% methanol, 10\% acetic acid) and fixed (5\% methanol, 7.5\% acetic acid). The digestion products were quantified with a computerised scanner.

\section{Preparation of conditioned media (CM)}

Confluent normal (GMO 6965) and desmoid (GMO 6888 ) fibroblasts were washed with $0.9 \% \mathrm{NaCl}$ and cultured for $12 \mathrm{~h}$ in serum-free MEM. This medium was discarded to avoid contamination by serum factors and cells were cultured for the next $24 \mathrm{~h}$ in MEM and ethanol (control) or in MEM containing $1 \mu \mathrm{M}$ toremifene in ethanol (final ethanol concentration $0.1 \% \mathrm{v} / \mathrm{v}$ ). Conditioned media (CM) were collected and centrifuged for $10 \mathrm{~min}$ at $350 \mathrm{~g}$ to remove cell debris, dialysed against bidistilled water for $24 \mathrm{~h}$, lyophilised and used for zymography and Western blot analysis as described below.

\section{Collagen and gelatin zymography}

CM were analysed for gelatinases and collagenases by zymography. Samples were separated under non reducing condition on $6 \%$ polyacrylamide gels containing $1 \mathrm{mg} / \mathrm{ml}$ of gelatin (Sigma Chemical, St Louis; MO, USA) or $1 \mathrm{mg} /$ $\mathrm{ml}$ collagen (Sigma) [20]. In one set of samples the proenzymatic forms were activated using $2 \mathrm{mM}$ aminophenylmercuric acetate (APMA) for $1 \mathrm{~h}$ at $37^{\circ} \mathrm{C}$. Samples were lyophilised and resuspended in Tris- $\mathrm{HCl} 0.4 \mathrm{M} \mathrm{pH}$ 6.8 , SDS 5\%, 20\% glycerol and 0.03\% bromophenol blue. Gels were loaded with $8 \mu \mathrm{g}$ protein per sample or with 2 $\mu \mathrm{g}$ trypsin and run under Laemmli conditions [21]. After electrophoresis, gels were washed twice in $200 \mathrm{ml}$ of $2.5 \%$ Triton X-100 (30 min each) under constant mechanical stirring and incubated in $50 \mathrm{mM}$ Tris- $\mathrm{HCl} \mathrm{pH} \mathrm{7.5,5} \mathrm{mM}$ $\mathrm{CaCl}_{2}, 0.02 \%$ Brij-35 and $200 \mathrm{mM} \mathrm{NaCl}$ at $37^{\circ} \mathrm{C}$ for $24 \mathrm{~h}$. Gels were stained with Coomassie brilliant blue G-250. Proteinase activity, observed as cleared (unstained) regions, was converted to dark regions to better observation of bands.

\section{Western-blot analysis}

CM were analysed for type I and type III collagen, MMP1, MMP-2, MMP-9, TIMP-1 and TIMP-2 by Western blotting using specific monoclonal antibodies. Aliquots of $\mathrm{CM}$, containing $50 \mu \mathrm{g}$ of proteins, were separated on SDS$10 \%$ polyacrylamide gels under reducing conditions and transferred on to a nitrocellulose membrane. The membrane was blocked with blocking solution $(5 \% \mathrm{w} / \mathrm{v}$ dried skimmed-milk powder in TBS $1 \mathrm{X}, 2 \mathrm{~h}$ at room temperature) and incubated with the specific monoclonal antibody in antibody solution (1\% w/v dried skimmed-milk powder in TBS $1 \mathrm{X}, 2 \mathrm{~h}$ at room temperature). Bound antibody was detected with a sheep anti-mouse peroxidaseconjugated antibody in antibody solution. Western analysis was performed using chemiluminescence reagents from Amersham Pharmacia Biotech.

\section{Protein determination}

Protein concentrations were determined by the Lowry assay [22] of aliquots of cell lysate.

\section{Statistical analysis}

In some experiments, statistical analysis was performed using Student's $t$-test. Data are expressed as the means \pm $\mathrm{SD}$ of four determinations. In other experiments, the results are reported as means \pm SD of three separate experiments, each performed in quadruplicate. Statistical analysis was performed by Student's two-tailed $t$-test and by analysis of variance (ANOVA) followed by Sheffe F-test.

\section{Results \\ Cell viability}

The amount of dead cells and viable cells in normal fibroblasts, desmoid fibroblasts and desmoid fibroblasts 
Table I: Cell viability

\begin{tabular}{llll}
\hline & Viable cells & Dead cells & \% of dead cells \\
\hline Normal fibroblasts & $1,224,805 \pm 56,280$ & $308 \pm 26$ & 0.025 \\
Desmoid fibroblasts & $1,636,710 \pm 84,105^{*}$ & $29 \pm 4$ & 0.0017 \\
Desmoid fibroblasts + toremifene & $1,393,900 \pm 86,400$ & $161 \pm 15$ & 0.011 \\
\hline
\end{tabular}

Fibroblasts were cultured for $24 \mathrm{~h}$ in MEM containing ethanol with or without toremifene. Number of viable and dead cells/culture after exposure to trypan blue for $15 \mathrm{~min}$. The values are the means \pm SD of five cultures. *Significance vs normal fibroblasts: $P<0.01$.

Table 2: ${ }^{3} \mathrm{H}$-proline incorporation into collagen fibres

\begin{tabular}{lll}
\hline & Cells & Media \\
\hline & $3 \mathrm{~h}$ & \\
\hline Normal fibroblasts & $1,060 \pm 85$ & $998 \pm 94$ \\
Desmoid fibroblasts & $885 \pm 60$ & $991 \pm 39$ \\
Desmoid fibroblasts + toremifene & $1,112 \pm 134$ & $837 \pm 36$ \\
\hline & $24 \mathrm{~h}$ & \\
\hline Normal fibroblasts & $2,313 \pm 99$ & $6,523 \pm 388$ \\
Desmoid fibroblasts & $3,340 \pm 205^{*}$ & $11,641 \pm 421^{*}$ \\
Desmoid fibroblasts + toremifene & $2,286 \pm 124^{\circ}$ & $9,962 \pm 644^{\circ 0}$ \\
\hline & $48 \mathrm{~h}$ & \\
\hline Normal fibroblasts & $4,262 \pm 280$ & $17,955 \pm 1,073$ \\
Desmoid fibroblasts & $5,649 \pm 103^{*}$ & $20,407 \pm 980^{\circ}$ \\
Desmoid fibroblasts + toremifene & $3,295 \pm 261^{\circ}$ & 1,32 F $^{\circ}$ \\
\hline
\end{tabular}

Fibroblasts were cultured for 3, 24 and $48 \mathrm{~h}$ in MEM containing ${ }^{3} \mathrm{H}$-proline with or without toremifene. Total radioactivity value is expressed in $\mathrm{cpm} / \mathrm{mg}$ protein and represents the mean \pm SD of three determinations, each in quadruplicate. The statistical analysis was performed with analysis of variance (ANOVA). Differences vs normal fibroblasts: F-test significant at *99\%; differences vs desmoid fibroblasts: F-test significant at ${ }^{\circ} 99 \%$, ${ }^{\circ} 95 \%$.

plus toremifene was evaluated after $24 \mathrm{~h}$ of in vitro maintenance in the presence of trypan blue (Table 1). Granted that the number of intact viable cells was high in all the experimental conditions, desmoid fibroblasts had the highest number of cells/culture and the lowest percentage of dead cells $(0.0014 \%)$. Treatment of desmoid fibroblasts with toremifene enhanced the percentage of dead cells $(0.011 \%)$ which, nevertheless, remained lower than in normal fibroblasts $(0.025 \%$.).

\section{Effects of toremifene on collagen synthesis}

Collagen synthesis was evaluated after 3, 24 and $48 \mathrm{~h}$ of in vitro maintenance in the presence of ${ }^{3} \mathrm{H}$-proline (Table 2). No significant difference was observed after 3 hours culture. After 24 and $48 \mathrm{~h}$ culture collagen production was significantly higher in desmoid than in normal fibroblasts, in both the cellular and extracellular compartments.
The increase was 1.4 fold in the cells and 1.8 fold in the medium after $24 \mathrm{~h} ; 1.3$ fold in the cells and 1.8 fold in the medium after $48 \mathrm{~h}$. Adding toremifene significantly decreased collagen synthesis at 24 and at $48 \mathrm{~h}$. The reduction was greater after $48 \mathrm{~h}(42 \%$ in the cells and $38 \%$ in the medium). In a second set of experiments desmoid fibroblasts were cultured for $48 \mathrm{~h}$ with or without toremifene. The radiolabelled precursor was added for 48 $\mathrm{h}$, in the last $24 \mathrm{~h}$ and in the last $3 \mathrm{~h}$ (Table 3). Treatment with toremifene had an inhibitory effect at all times. The decrease in total collagen (cells + media) in desmoid fibroblasts treated with toremifene was $28 \%$ in the presence of ${ }^{3} \mathrm{H}$-proline for $48 \mathrm{~h}, 46 \%$ and $52 \%$ respectively in the presence of ${ }^{3} \mathrm{H}$-proline in the last 24 or $3 \mathrm{~h}$ of in vitro maintenance (Table 3 ). 
Table 3: ${ }^{3} \mathrm{H}$-proline incorporation into collagen fibres

\begin{tabular}{|c|c|c|c|}
\hline & Cells & Media & Cells + Media \\
\hline & $48 \mathrm{~h}$ & & \\
\hline Desmoid fibroblasts & $6,852 \pm 290$ & $33,915 \pm 2,307$ & 40,767 \\
\hline Desmoid fibroblasts + toremifene & $\begin{array}{l}4,243 \pm 36 I^{*} \\
24 \mathrm{~h}\end{array}$ & $25,097 \pm 814^{*}$ & 29,340 \\
\hline Desmoid fibroblasts & $4,252 \pm 416$ & $15,423 \pm 1,100$ & 19,675 \\
\hline Desmoid fibroblasts + toremifene & $\begin{array}{l}1,432 \pm 101 * \\
3 \mathrm{~h}\end{array}$ & $9,221 \pm 38 I^{*}$ & 10,653 \\
\hline Desmoid fibroblasts & $1,176 \pm 48$ & $1,498 \pm 56$ & 2,674 \\
\hline Desmoid fibroblasts + toremifene & $534 \pm 31 *$ & $745 \pm 74^{*}$ & 1,279 \\
\hline
\end{tabular}

Fibroblasts were cultured for $48 \mathrm{~h}$ in MEM with or without toremifene. ${ }^{3} \mathrm{H}$-proline was added for $48 \mathrm{~h}$, for the last $24 \mathrm{~h}$ and for the last $3 \mathrm{~h}$. Total radioactivity value is expressed in $\mathrm{cpm} / \mathrm{mg}$ protein and represents the mean \pm SD of three determinations, each in quadruplicate. The statistical analysis was performed with analysis of variance (ANOVA). Differences vs desmoid fibroblasts: F-test significant at *99\%.

\section{Procollagen $\alpha_{1}(\mathrm{I})$ mRNA expression}

Northern blots were performed to analyse procollagen $\alpha_{1}$ (I) mRNA level in normal and desmoid fibroblasts (Fig. 1). Relative densitometric units were normalised to GAPDH mRNA levels. Normal and desmoid fibroblasts exhibited no significant differences in the steady-state mRNA levels for procollagen $\alpha_{1}(\mathrm{I})$. Toremifene down regulated procollagen mRNA expression by $58 \%$ in desmoid cells.

\section{Western-blot analysis of type I and III collagen}

Media from normal and desmoid fibroblasts with or without toremifene were analysed by Western blotting to evaluate the presence of type I and III collagen using specific monoclonal antibodies (Fig. 2). Densitometric tracing of the autoradiograms quantified collagen secretion. Desmoid fibroblasts secreted much more type I (1.6 fold) and III (2.2 fold) collagen than normal cells. Toremifene reduced type I and III collagen by $31 \%$ and $18 \%$ respectively in desmoid fibroblasts.

\section{Collagenase activity}

Collagenases, from ammonium sulphate-precipitated proteins of media of normal fibroblasts, desmoid fibroblasts and desmoid fibroblasts treated with toremifene, were incubated with soluble collagen and the digested products were evaluated by gel electrophoresis. Collagenases in the medium of normal fibroblasts digested more $\alpha_{1}$ and $\alpha_{2}$ chains of type I collagen into their corresponding $3 / 4$ and $1 / 4$ fragments than the collagenase in desmoid fibroblasts (Fig. 3). When band staining intensity was quantified by densitometry, the abundance of the $3 / 4$ and $1 / 4$ products of collagenase digestion was significantly greater in normal than in desmoid fibroblasts. Adding toremifene to desmoid fibroblasts markedly increased collagenase activity as shown by the increased amount of $3 / 4$ and $1 / 4$ fragments of $\alpha_{1}$ and $\alpha_{2}$ chains (Fig. 3 ).

\section{Collagen and gelatin zymography}

Collagen and gelatin zymograms dosed the enzymatic activity of collagenases and gelatinases. Collagen zymogram, reported in Fig. 4 (panel A and B), showed the samples produced a band of $52 \mathrm{kDa}$ corresponding to MMP1. Densitometric analysis of the counts, assuming the value of normal fibroblasts as $100 \%$, demonstrated 2.3 fold increase in the $52 \mathrm{kDa}$ collagenase activity in desmoid fibroblasts. When desmoid fibroblasts were treated with toremifene, the level of collagenase activity in the media was only minimally affected. No bands were present in trypsin (Fig. 4, panel A, line C), which can degrade gelatin but not collagen, confirming that collagen has been degraded in panel A. The gelatin zymogram (Fig. 4 , panel C and D) showed two bands, one of $92 \mathrm{kDa}$ corresponding to MMP-9, the other of $66 \mathrm{kDa}$ corresponding to MMP-2. Desmoid fibroblasts produced the same amount of MMP-9, and larger (about 2 fold) amounts of MMP-2, than normal fibroblasts Adding toremifene to desmoid fibroblasts increased only MMP-2 activity by about 1.32 fold. To verify whether the bands detected in the collagen and gelatin zymography were due only to MMPs, two control gels were washed and incubated in buffers containing $10 \mathrm{mM}$ EDTA. No bands were detected after this treatment, which indicated that the bands obtained in collagen and gelatin zymographies were entirely due to MMP activity. Toremifene addition to desmoid cells was accompanied by no changes in gelatinase activity. One set of samples in collagen and gelatin zymograms was treated with APMA to activate the proenzymes. Activation of the proenzymatic form had no significant effects on collagenase activity (Fig. 4, panel B), but 
A.

\section{NF DF DFT}
Pro $\alpha_{1}(\mathrm{I})$
$5.8 \mathrm{~kb}-$
$4.7 \mathrm{~kb}-$

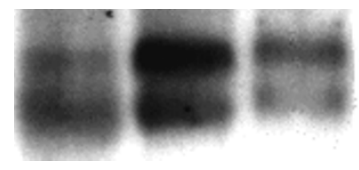

GAPDH

$1.3 \mathrm{~kb}-$

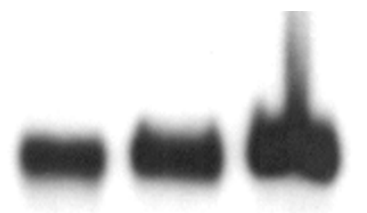

B.

\begin{tabular}{|c|c|}
\hline & Pro-collagen $\alpha_{1}(\mathrm{I}) / \mathrm{GAPDH}$ \\
\hline Normal fibroblasts & 100 \\
\hline Desmoid fibroblasts & 106 \\
\hline Desmoid fibroblasts plus toremifene & 44 \\
\hline
\end{tabular}

\section{Figure I}

Expression of procollagen $\alpha_{1}(I)$ and glyceraldehydes-3-phosphate dehydrogenase (GAPDH) mRNA in normal and desmoid fibroblasts. Panel A: NF: normal fibroblasts; DF: desmoid fibroblasts; DFT: desmoid fibroblasts plus toremifene. Similar results were obtained in four separate experiments. In panel B the absolute counts, obtained by densitometric analysis, were converted to percentages of control value, assuming the untreated level of normal fibroblasts as $100 \%$.

enhanced gelatinase activity in desmoid fibroblasts (Fig. 4, panel D).

\section{Western-blot analysis of MMP-I, MMP-2, MMP-9}

The presence of MMP-1, MMP-2, MMP-9 in the media of normal fibroblasts, desmoid fibroblasts and desmoid fibroblasts plus toremifene was evaluated by Western-blot analysis using specific monoclonal antibodies (Fig. 5). Western blot analysis of MMP-1 (Fig. 5, panel A) showed that the amount of the protein was higher in desmoid (2 fold) and in desmoid than in normal fibroblasts ( 2 fold). Toremifene exhibited no significant increase of MMP-1 in desmoid cells (about 2.2 fold). MMP-2 (Fig. 5, panel B) showed two bands, the first due to the proenzymatic form (72 $\mathrm{kDa}$ ) and the second to the active form (66 kDa). MMP-2 was significantly increased in desmoid fibroblasts (2.2 fold) and even more in desmoid fibroblasts plus 
A.

NF DF DFT

Type I collagen $95 \mathrm{kDa} \rightarrow$

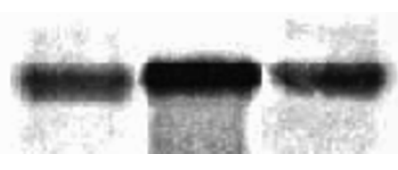

NF DF DFT

Type III collagen $110 \mathrm{kDa} \rightarrow$

B.

\begin{tabular}{|l|c|c|}
\hline & Type I collagen & Type III collagen \\
\hline Normal fibroblasts & 100 & 100 \\
\hline Desmoid fibroblasts & 161 & 220 \\
\hline Desmoid fibroblasts plus toremifene & 110 & 181 \\
\hline
\end{tabular}

Figure 2

Western blot analysis of type I and III collagen secreted into the medium by normal and desmoid fibroblasts. Panel A. The samples are as follow: NF normal fibroblasts; DF desmoid fibroblasts; DFT desmoid fibroblasts plus toremifene. Similar results were obtained in four separate experiments. Panel B. The absolute counts, obtained by densitometric analysis, were converted to percentages assuming the level of normal fibroblasts as $100 \%$. 
A.

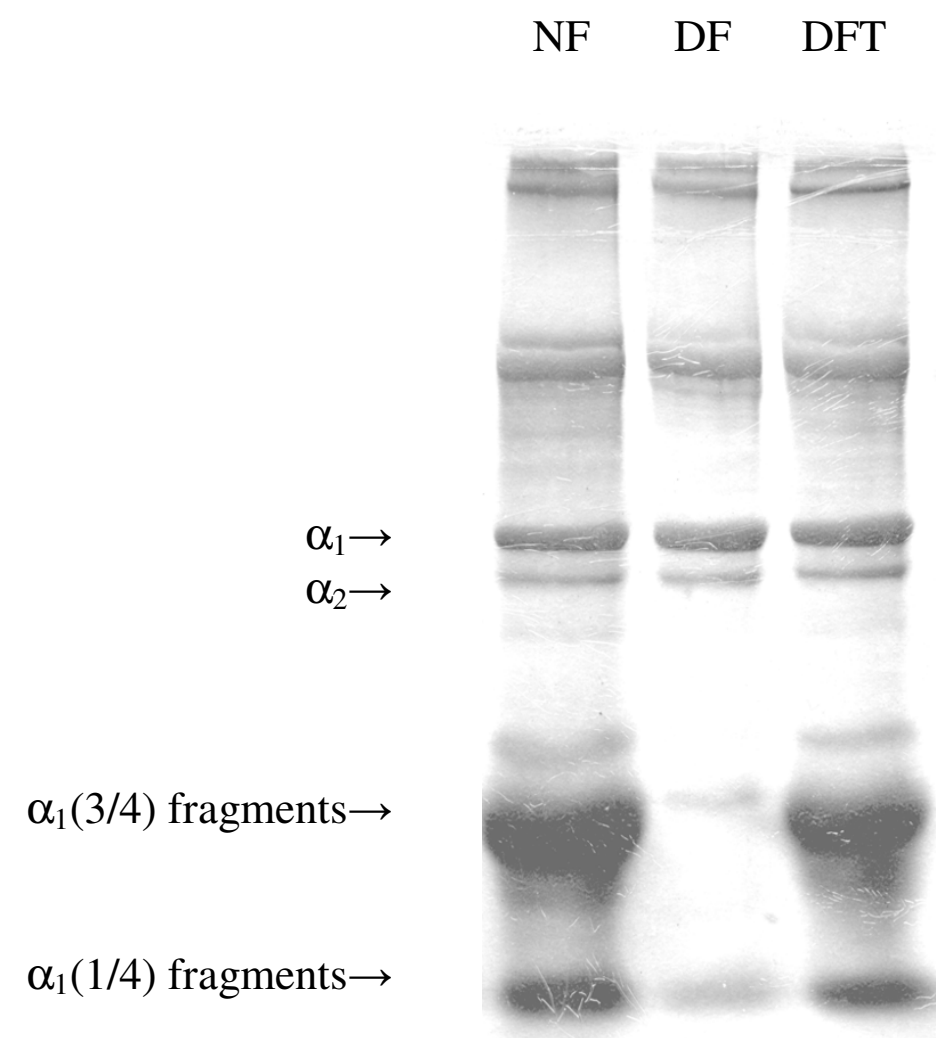

B.

\begin{tabular}{|l|c|c|c|}
\hline & $\begin{array}{c}\text { Normal } \\
\text { fibroblasts }\end{array}$ & $\begin{array}{c}\text { Desmoid } \\
\text { fibroblasts }\end{array}$ & $\begin{array}{c}\text { Desmoid } \\
\text { fibroblasts plus } \\
\text { toremifene }\end{array}$ \\
\hline$\alpha_{1}(3 / 4)$ fragments & 100 & 22 & 80 \\
\hline$\alpha_{1}(1 / 4)$ fragments & 100 & 25 & 75 \\
\hline
\end{tabular}

\section{Figure 3}

Collagenase activity in media derived from normal, desmoid fibroblasts and desmoid fibroblasts plus toremifene. Panel A. NF: normal fibroblasts; DF: desmoid fibroblasts; DFT: desmoid fibroblasts plus toremifene. Similar results were obtained in four separate experiments. In panel B the quantity of 3/4 and I/4 fragments of digested collagen was determined by densitometric analysis. The absolute counts were converted to percentages assuming the level of normal fibroblasts as $100 \%$. 
A.

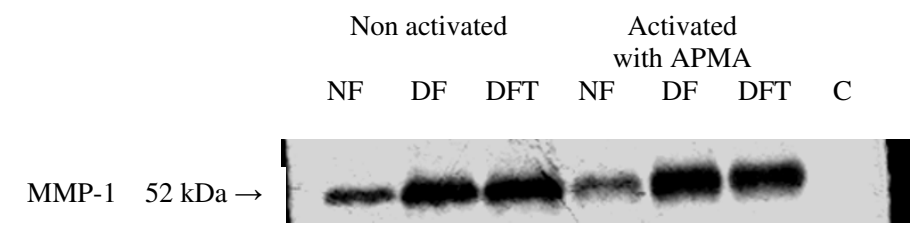

B.

\begin{tabular}{|c|c|c|}
\hline & Non activated & $\begin{array}{c}\text { Activated } \\
\text { with APMA }\end{array}$ \\
\hline Normal fibroblasts & 100 & 100 \\
\hline $\begin{array}{c}\text { Desmoid fibroblasts } \\
\begin{array}{c}\text { Desmoid fibroblasts plus } \\
\text { toremifene }\end{array}\end{array}$ & 235 & 236 \\
\hline \multicolumn{2}{|c}{} \\
\hline
\end{tabular}

C.

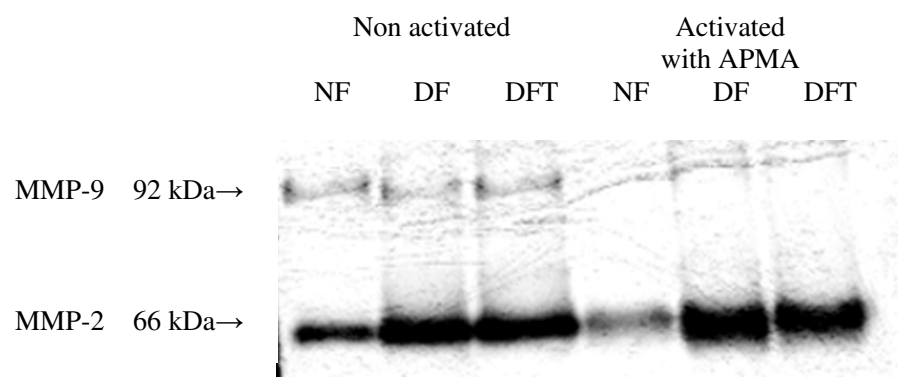

D.

\begin{tabular}{|l|c|c|c|c|}
\hline \multirow{2}{*}{} & \multicolumn{2}{|c|}{ Non activated } & \multicolumn{2}{c|}{$\begin{array}{c}\text { Activated with } \\
\text { APMA }\end{array}$} \\
\cline { 2 - 5 } & MMP-2 & MMP-9 & MMP-2 & MMP-9 \\
\hline Normal fibroblasts & 100 & 100 & 100 & 100 \\
\hline Desmoid fibroblasts & 195 & 97 & 261 & 105 \\
\hline Desmoid fibroblasts plus toremifene & 259 & 102 & 251 & 98 \\
\hline
\end{tabular}

\section{Figure 4}

Zymogram of media from normal fibroblasts, desmoid fibroblasts, desmoid fibroblasts plus toremifene. Collagen zymogram. One set of samples was treated with APMA to activate the proenzymatic forms. Panel A. NF: normal fibroblasts, DF: desmoid fibroblasts, DFT: desmoid fibroblasts plus toremifene. In the same zymogram an aliquot of samples was activated with APMA: NF: normal fibroblasts, DF: desmoid fibroblasts, DFT: desmoid fibroblasts plus toremifene, C: trypsin. Similar results were obtained in four separate experiments. Panel B. The absolute counts, obtained by densitometric analysis, were converted to percentages assuming the level of normal fibroblasts as $100 \%$. Gelatin zymogram. One set of samples was treated with APMA to activate the proenzymatic forms. Panel C. NF: normal fibroblasts, DF: desmoid fibroblasts, DFT: desmoid fibroblasts plus toremifene. In the same zymogram an aliquot of samples was activated with APMA: NF: normal fibroblasts, DF: desmoid fibroblasts, DFT: desmoid fibroblasts plus toremifene. Similar results were obtained in four separate experiments. Panel D. The absolute counts, obtained by densitometric analysis, were converted to percentages assuming the level of normal fibroblasts as $100 \%$. 
A.

$$
\text { MMP-1 } 52 \mathrm{kDa} \rightarrow
$$

\section{NF DF DFT}

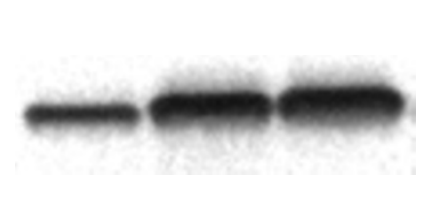

B.

$$
\text { NF DF DFT }
$$

$$
\begin{array}{ll}
\text { MMP-2 } & 72 \mathrm{kDa} \rightarrow \\
& 66 \mathrm{kDa} \rightarrow
\end{array}
$$

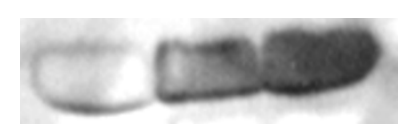

C.

\section{NF DF DFT}

$$
\text { MMP-9 } 92 \mathrm{kDa} \rightarrow
$$

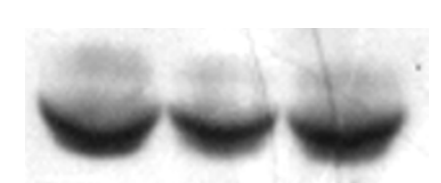

D.

\begin{tabular}{|l|c|c|c|}
\hline & MMP-1 & MMP-2 & MMP-9 \\
\hline Normal fibroblasts & 100 & 100 & 100 \\
\hline Desmoid fibroblasts & 200 & 220 & 91 \\
\hline Desmoid fibroblasts plus toremifene & 223 & 332 & 97 \\
\hline
\end{tabular}

\section{Figure 5}

Western blot analysis of MMP-I, MMP-2, MMP-9 secreted into the medium. Panel A: MMP-I; panel B: MMP-2; panel C: MMP-9. The samples are as follows: NF, normal fibroblasts; DF, desmoid fibroblasts; DFT, desmoid fibroblasts plus toremifene. Similar results were obtained in four separate experiments. Panel $D$. The absolute counts, obtained by densitometric analysis, were converted to percentages assuming the level of normal fibroblasts as $100 \%$. ND $=$ not determined. 
toremifene ( 3.2 fold) compared with normal fibroblasts. No significant differences emerged in the production of MMP-9 (Fig. 5, panel C).

\section{Western-blot analysis of TIMP-I and TIMP-2}

Western blot analysis showed that desmoid fibroblasts produced about 7.2 and 3.4 fold TIMP-1 (Fig. 6, panel A) and TIMP-2 respectively (Fig. 6, panel B) than normal fibroblasts. Adding toremifene to desmoid fibroblasts decreased TIMP-1 by 18\%, but had no effect on TIMP-2.

\section{Discussion}

Desmoid tumour is a benign non-invasive and nonmetastasising neoplasm with an abnormal ECM macromolecule deposition which is stimulated by TGF $\beta_{1}$ $[3,23,24]$. The regulation of extracellular matrix dynamics is clearly complicated, involving a balance between the deposition of structural components such as collagen and their degradation by MMPs, i.e. collagenases and gelatinases. MMP activity is itself regulated by a variety of mechanisms, including a requirement for enzyme modification to elicit maximal enzymatic activity and the activity of specific TIMPs [25]. There is now evidence that desmoid cells undergo dramatic clinical response to toremifene, implying the drug has a direct effect upon fibroblasts. Our previous studies showed that toremifene significantly inhibited TGF $\beta_{1}$ activity which was six fold higher in desmoid than in normal fibroblasts [3]. As desmoid tumour is also associated with abnormal collagen production [26], in the present study we examined the rate of collagen synthesis and degradation in the presence or absence of toremifene. In our experimental conditions, type I and III collagen accumulation in the intra- and extra-cellular compartments showed no differences after 3 $\mathrm{h}$ of in vitro maintenance, but increased significantly more after 24 and $48 \mathrm{~h}$ in desmoid fibroblasts than in normal fibroblasts. No increase in collagen after 3 hours suggests its accumulation in desmoid fibroblasts is due to inhibition of degradation rather than to increased synthesis. The results are confirmed by procollagen $\alpha_{1}$ (I) gene expression, which showed mRNA levels were only lower in desmoid cells treated with toremifene. Normal and desmoid fibroblasts expressed different amounts of MMPs. Several studies suggest that MMPs are overexpressed in malignant tumour progression and facilitate both local tumour invasion and metastasis $[27,28]$. Different MMPs may play distinct roles at different stages of tumour development [29]. They may form a network, in which a single MMP is crucial for the cleavage of certain native or partially degraded matrix components and for the activation of other latent MMPs. MMP-1 plays a pivotal role in cancer progression and poor prognosis in colon-rectal, oesophageal and gastric cancer has been correlated with high MMP-1 expression [25,30]. Nishiota [31] showed MMP-1 is expressed more strongly in the cancer front of invasion. MMP-2 is increased in cancer tissue and its over-expression is correlated with tumourrelated basement membrane degradation and vascular invasion $[32,33]$. Therefore inhibition of the expression or activity of only one MMP could potentially reduce peritumoural proteolytic activity and tumour invasion [34]. In this study we investigated the metalloproteinases most involved in type I collagen degradation, i.e. MMP-1 (collagenase-1), MMP-2 (gelatinase-A) and MMP-9 (gelatinase-B) and their natural inhibitors TIMP-1 and TIMP-2 [11]. Moreover TIMP-2 is 10-fold more potent than TIMP1 against MMP-2 [11] which is involved either in the final degradation of native collagen or in the initial degradation cleaving native type I collagen to $3 / 4$ and $1 / 4$ fragments identical to those generated by MMP-1 [12]. Using Western blot we showed no differences in MMP-9 production, while MMP-1 and MMP-2 were higher in desmoid than in normal fibroblasts. Collagen and gelatin zymograms, in which the proteolytic enzymes were separated from TIMPs before the assay, proved the activities of collagenase MMP-1 and gelatinase MMP-2, as dosed in conditioned media, were higher in desmoid than in normal fibroblasts. However, collagenase activity, in the presence of TIMPs, was reduced in desmoid compared to normal fibroblasts as shown by the lower amount of $3 / 4$ and $1 / 4$ fragments of fibrillar collagen in desmoid cells. Together these results indicated the higher MMP-1 and MMP-2 activity in desmoid cells was masked by a 7 -fold increase in TIMP-1 and a 3-fold increase in TIMP-2. TIMP1 is a potent inhibitor of apoptosis in many cells types, its up-regulation protects the cells against apoptotic stimuli [35]; hence, greater number of viable cells in desmoid tumour.

Upregulation in both inhibitors of MMPs may explain why the Desmoid tumour is characterised by an abundant deposition of ECM macromolecules and is neither malignant nor invasive. Toremifene addition to desmoid fibroblasts reduced the accumulation of collagen fibres but its mechanism of action remains unclear. Toremifene increased MMP-1 and MMP-2 activity by $8 \%$ and $25 \%$ respectively and decreased TIMP-1 by $18 \%$. Despite these modest effects type I collagen degradation in $3 / 4$ and $1 / 4$ fragments increased almost 4 -fold.

\section{Conclusion}

Our previous studies showed that TGF $\beta_{1}$ was 6 -fold higher in desmoid than in normal fibroblasts and that toremifene significantly reduced TGF $\beta_{1}$ activity and TGF $\beta_{1}$ membrane-receptors [3]. So the effects of toremifene on MMPs and TIMPs could be linked to its effects on TGF $\beta_{1}$ because the growth factor enhances organic macromolecule accumulation in the ECM via a reduction in MMP-1 and MMP-2 [36] and an increase in TIMP-1 [37], so favouring tumour mass growth through an inhibition of 
A.

\section{NF DF DFT}

TIMP-1 $30 \mathrm{kDa} \rightarrow$

B.

NF DF DFT

TIMP-2 $18 \mathrm{kDa} \rightarrow$

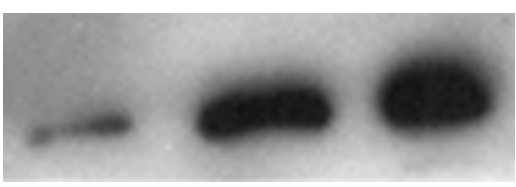

C.

\begin{tabular}{|l|c|c|}
\hline & TIMP-1 & TIMP-2 \\
\hline Normal fibroblasts & 100 & 100 \\
\hline Desmoid fibroblasts & 735 & 343 \\
\hline Desmoid fibroblasts plus toremifene & 603 & 358 \\
\hline
\end{tabular}

Figure 6

Western blot analysis of TIMP-I and TIMP-2 secreted into the medium. Panel A; TIMP-I. Panel B; TIMP-2. The samples are as follows: NF, normal fibroblasts; DF, desmoid fibroblasts; DFT, desmoid fibroblasts plus toremifene. Similar results were obtained in four separate experiments. Panel C. The absolute counts, obtained by densitometric analysis, were converted to percentages assuming the level of normal fibroblasts as $100 \%$. 
ECM macromolecule degradation. In the light of these data the reduction of organic macromolecules in the ECM in the presence of toremifene can be ascribed to its inhibition not only of collagen synthesis, but also of TGF $\beta_{1}$ activity. Further studies on the regulation of MMP activities may clarify the role of toremifene on ECM degradation and provide important clues about pathogenesis of desmoid tumour.

\section{Competing interests}

The author(s) declare that they have no competing interests.

\section{Authors' contributions}

$\mathrm{CB}$ carried out collagen synthesis, collagenase activity and drafted the manuscript.

CL and GB participated in the design of the study and carried out Northern blot analysis.

LM and GG carried out RT-PCR, zimography and oestrogen receptor assay.

$\mathrm{AB}$ and LC carried out Western blot analysis and performed the statistical analysis.

PL conceived of the study, and participated in its design and coordination.

All authors read and approved the final manuscript.

\section{Acknowledgements}

We thank Dr. G.A. Boyd for help with the English translation.

\section{References}

I. Eccles DM, Van Der Luijt R, Breukel C, Bullman H, Bunyan D, Fisher A, Barber J, Boulayc DU, Primrose J, Burn J, Fodde R: Hereditary desmoid disease due to a frameshift mutation at codon 1924 of the APC gene. Am J Hum Genet 1996, 59:I I93-I201.

2. Lewis J], Boland PJ, Leung DH, Woodruff JM, Brenna MF: The enigma of desmoid tumors. Ann Surg 1999, 229:866-878.

3. Locci P, Bellocchio S, Lilli C, Marinucci L, Cagini L, Baroni T, Giustozzi $\mathrm{G}$, Becchetti E: Synthesis and secretion of transforming growth factor- $\beta$ I by human desmoid fibroblast cell line and its modulation by toremifene. J Interf Cytok Res 2001, 2 I:961-970.

4. Massagué J, Blain SW, Lo RS: TGF $\beta$ signalling in growth control, cancer and heritable disorders. Cell 2000, I 03:295-309.

5. Pasque B: Role of TGF-beta in cancer. J Cell Physiol 200I, 186:53-168.

6. Lilli C, Marinucci L, Bellocchio S, Ribatti D, Balducci C, Baroni T, Cagini L, Locci P: Effects of tranforming growth factor-bI and tumour necrosis factor-a on cultured fibroblasts from skin fibroma as modulated by toremifene. Int J Cancer 2002, 98:824-832.

7. Birkedal-Hansen H, Moore WGI, Bodden MW, Windsor LJ, BirkedalHansen B, DeCarlo A, Engler JA: Matrix metalloproteinases: a review. Crit Rev Oral Biol Med 1993, 4:197-250.

8. Mao D, Lee JK, VanVickle SJ, Thompson W: Expression of collagenase-3 (MMP-I3) in human abdominal aortic aneurysms and vascular smooth muscle cells in culture. Biochem Bioph Res Co 1999, 261:904-910.
9. Kahari VM, Saarialho-Kere U: Matrix metalloproteinases and their inhibitors in tumour growth and invasion. Ann Med 1999 , 3 I:34-35.

10. Shapiro SD: Matrix metalloproteinase degradation of extracellular matrix: biological consequences. Curr Opin Cell Bio 1998, 1 0:602-608

II. Veli-Matti K, Saarialho-Kere U: Matrix metalloproteinases and their inhibitors in tumour growth and invasion. Ann Med 1999 , 3 I:34-45.

12. Aimes RT, Quigley JP: Matrix metalloproteinase is an interstitial collagenase. J Biol Chem 1995, 270:5872-5876.

13. Gomez DE, Alonso DF, Yoshiji H, Thorgeirsson UP: Tissue inhibitors of metalloproteinases: structure, regulation and biological functions. Eur J Cell Biol 1997, 74: I II-I22.

14. Eickelberg O, Kohler E, Reichenberger F, Bertschin S, Woodtli T, Erne P, Perruchoud AP, Roth M: Extracellular matrix deposition by primary human lung fibroblasts in response to TGF- $\beta_{1}$ and TGF- $\beta_{3}$. Am J Physiol 1999, 276:8|4-824.

15. Brooks MD, Ebbs SR, Colletta AA, Baum M: Desmoid tumours treated with triphenylethylenes. Eur J Cancer 1992, 28:1014-1018.

16. Serpell JW, Paddle Ledinek JE, Johnson WR: Modification of growth of desmoid tumours in tissue culture by anti-oestrogenic substances: a preliminary report. Aust N Z J Surg 1996, 66:457-463.

17. Webster DF, Harvey WA: A quantitative assay for collagen synthesis in micro-well fibroblast cultures. Anal Biochem 1979, 96:220-224.

18. Chomczynski P, Sacchi N: Single step method of RNA isolation by acid guanidinium thiocyanate-phenol-chloroform extraction. Anal Biochem 1987, I62:|56-I59.

19. Khorramizadeh MR, Tredget EE, Telasky C, Shen Q, Ghahary A: Aging differentially modulates the expression of collagen and collagenase in dermal fibroblasts. Mol Cell Biochem 1999, 194:99-108.

20. Gogly B, Groult N, Hornebeck W, Godeau G, Pellat B: Collagen zymography as a sensitive and specific technique for the determination of subpicogram levels of interstitial collagenase. Anal Bioch 1998, 255:21 1-216.

21. Laemmli UK: Cleavage of structural proteins during the assembly of the head of bacteriophage T4. Nature 1970, 227:680-685

22. Lowry OH, Rosebrough NJ, Farr AJ, Randall RJ: Protein measurement with the folin phenol reagent. J Biol Chem I95I, 193:265-275.

23. Bodo M, Carinci P, Baroni T, Bellucci C, Giammarioli C, Pezzetti F, Becchetti E: Role of growth factors on extracellular matrix production by chick embryo fibroblasts in vitro. Antagonist effect of TGF- $\beta$ through the control of IL-I and IL-IRa secretion. Cytokine 1998, I0:353-360.

24. Locci P, Baroni T, Lilli C, Martinese D, Marinucci L, Bellocchio S, Calvitti $M$, Becchetti E: TGF- $\beta$ and TGF- $\alpha$, antagonist effect in vitro on extracellular matrix accumulation by chick skin fibroblasts at two distinct embryonic stages. Int J Dev Biol 1999, 43: $157-165$.

25. Murray GI, Duncan ME, Arbuckle E, Melvin WT, Tothergill JE: Matrix metalloproteinases and their inhibitors in gastric cancer. Gut 1998, 43:79|-797.

26. Naito Y, Ohori K, Tanaka M, Kamo T, Baba S, Hori T, Hashizume K Sugimura $\mathrm{H}$ : Collagen and elastin synthesis by desmoid tumour in vitro. Pathol Int 1998, 48:603-610.

27. Johnsen M, Lund LR, Romer J, Almholt K, Dano K: Cancer invasion and tissue remodelling: common themes in proteolytic matrix degradation. Curr Opin Cell Biol 1998, 10:667-67I.

28. Schmalfeldt B, Prechtel D, Harting K, Spathe K, Rutke S, Konik E, Fridman R, Berger U, Schmitt M, Kuhn W, Lengyel E: Increased expression of matrix metalloproteinases (MMP)-2, MMP-9, and the urokinase-type plasminogen activator is associated with progression from benign to advanced ovarian cancer. Clin Cancer Res 200I, 7:2396-2404.

29. Nemeth JA, Yousif R, Herzog M, Che M, Upadhyay J, Shekarriz B, Bhagat S, Mullins C, Fridman R, Cher ML: Matrix metalloproteinase activity, bone matrix turnover, and tumor cell proliferation in prostate cancer bone metastasis. Cancer Spectrum 2002, 94: $17-25$. 
30. Skiles JW, Gonnella NC, Jeng AY: The design, structure and therapeutic application of matrix metalloproteinase inhibitors. Curr Med Chem 200I, 8:425-474.

31. Nishioka $Y$, Sagae S, Nishikawa A, Ishioka S, Kudo R: A relationship between matrix metalloproteinase-I (MMP-I) promoter polymorphism and cervical cancer progression. Cancer Lett 2003, 200:49-55.

32. Kanayama H, Yokota K, Kurokawa Y, Murakami Y, Nishitani M, Kagawa S: Prognostic values of matrix metalloproteinase-2 and tissue inhibitor of metalloproteinase-2 expression in bladder cancer. Cancer 1998, 82:1359-1366.

33. Bernardo MM, Fridman R: TIMP-2 (tissue inhibitor of metalloproteinase-2) regulates MMP-2 (matrix metalloproteinase2) activity in the extracellular environment after pro-MMP-2 activation by MTI (membrane type I)-MMP. Biochem J 2003, 374:739-735.

34. Dong Z, Nemeth JA, Cher ML, Palmer KC, Bright RC, Fridman R: Differential regulation of matrix metalloproteinase-9, tissue inhibitor of metalloproteinase-I (TIMP-I) and TIMP-2 expression in co-cultures of prostate cancer and stromal cells. Int J Cancer 200 I, 93:507-5 I5.

35. Liu XW, Bernardo MM, Fridman R, Kim HR: Tissue inhibitor of metalloproteinase-I protects human breast epithelial cells against intrinsic apoptotic cell death via the focal adhesion kinase/phosphatidylinositol 3-kinase and MAPK signaling pathway. J Biol Chem 2003, 278:40364-72.

36. Cotrim P, de Andrade CR, Martelli-Junior H, Graner E, Sauk JJ, Coletta RD: Expression of matrix metalloproteinases in cyclosporin-treated gingival fibroblasts is regulated by transforming growth factor (TGF)-beta I autocrine stimulation. J Periodontol 2002, 73:1313-1322

37. Hirata M, Sato T, Tsumagari M, Shimada A, Nakano H, Hashizume K Ito A: Differential regulation of the expression of matrix metalloproteinases and tissue inhibitors of metalloproteinases by cytokines and growth factors in bovine endometrial stromal cells and trophoblast cell line BT-I in vitro. Biol Reprod 2003, 68:|276-|28|

\section{Pre-publication history}

The pre-publication history for this paper can be accessed here:

http://www.biomedcentral.com/1471-2407/5/22/prepub

\section{Publish with Bio Med Central and every scientist can read your work free of charge}

"BioMed Central will be the most significant development for disseminating the results of biomedical research in our lifetime. "

Sir Paul Nurse, Cancer Research UK

Your research papers will be:

- available free of charge to the entire biomedical community

- peer reviewed and published immediately upon acceptance

- cited in PubMed and archived on PubMed Central

- yours - you keep the copyright 